\title{
O tratamento da forma e do conteúdo de fotografias em fundos de arquivos: pressupostos teórico-metodológicos
}

The form and content treatment of photographs in archival funds: theoretical-methodological presuppositions.

\section{Irisneide de Oliveira Souza SILvA (1), Mariângela Spotti Lopes FuJITA (2) e Maria Leandra BIZELLO (3)}

(1) Universidade Estadual Paulista Júlio de Mesquita Filho - UNESP, Faculdade de Filosofia e Ciências, Departamento de Ciência da Informação - Programa de Pós-Graduação em Ciência da Informação, Av. Hygino Muzzi Filho, 737, Campus Universitário, CEP. 17525900 - Marília, SP, Brasil, Caixa-Postal: 421.

(1) irisneidesilva@yahoo.com.br; (2) fujita@marilia.unesp.br; (3) mleandra23@gmail.com

\section{Resumen}

Se investigan los presupuestos teórico-metodológicos del tratamiento de fotografías en fondos de archivos. La metodología consistió en revisión de la literatura que discute la ontología del proceso fotográfico, los aspectos teóricos y metodológicos del análisis de contenido, y la cuestión del tratamiento documental desde la perspectiva de la Archivística. Se constató se que el análisis de la forma y del contenido asociada a la teoría Archivística presenta elementos significativos que deben ser considerados en la construcción de una propuesta teórico-metodológica para el tratamiento de las fotografías en los fondos de archivos.

Palabras clave: Archivística. Fotografía. Forma y contenido. Identificación. Organización y Representación.

\section{Introdução}

As demandas colocadas pelas sociedades governamental e não-governamental atribuem ao arquivo a responsabilidade de promover a distribuição e o acesso ao patrimônio documental, do nível local ao global. Assim, emerge, no cenário de discussões da Ciência da Informação, e principalmente da Arquivística, a necessidade de fomentar discussões sobre como tratar os documentos fotográficos conforme os princípios teóricos e metodológicos da Arquivística, já que a mesma possui todo corpo teórico e um método próprio para tratar os documentos de um fundo documental. Conforme pesquisa anterior (Silva e Fujita, 2007) verificou-se que os grandes manuais se limitam a considerar que os documentos fotográficos devem receber 0 mesmo tratamento dado aos documentos textuais. Contatou-se também que a carência de estudos e o uso de diversos métodos utilizados

\begin{abstract}
The theoretical-methodological aspects of the treatment of photographs in archival holdings are researched. A literature review was done in three subjects: the photographic process, content analysis theory and methodology and archival cataloguing. It was verified that cataloguing of photographs in archives present idiosyncratic characteristics that must be taken into account.
\end{abstract}

Keywords: Archival Science. Photography. Form and content. Identification. Organization and representation.

para tratar as fotografias em ambientes de arquivos (Smit, 1996) têm colaborado para aumentar as dificuldades e inseguranças de arquivistas e instituições em relação ao processo de tratamento documental de fotografias na perspectiva da Arquivística. Dentre os vários problemas pontua-se aqui a questão da forma e do conteúdo de fotografias em fundos de arquivos, por ser um problema não equacionado pela teoria e pela prática da Arquivística.

Assim, o objetivo desse ensaio é investigar os pressupostos teórico-metodológicos da forma e do conteúdo de fotografias que forneçam subsídios para o desenho de uma proposta teórica e metodológica que viabilize o processo de tratamento de fotografias em fundos de arquivos. A construção dessa proposta é concebida como uma das condições para que profissionais e instituições venham efetivamente a atender as demandas colocadas pela sociedade em rela- 
ção aos conteúdos informacionais imagéticos de fundos arquivísticos.

Convém lembrar que na teoria Arquivística o conceito de fundo compreende o conjunto total de documentos produzidos, recebidos e acumulados por uma pessoa física ou jurídica, pública ou privada, que se originaram como produto de suas atividades e funções desenvolvidas durante a sua existência. Desse modo, o conjunto de documentos fotográficos produzidos e acumulados pela Faculdade de Filosofia e Ciência FFC Campus de Marília faz parte do arquivo, ou Fundo, Faculdade de Filosofia e Ciências, já que os referidos documentos possuem os atributos que os legitimam como documentos de arquivo.

O desenvolvimento do trabalho compreendeu a abordagem sobre a ontologia do processo fotográfico com base nos estudos de Dubois (1994) e Aumont (2004), na qual se procurou compreender a gênese da noção da forma e do conteúdo para representação de fotografias. Com base nos estudos do primeiro autor enfatizou-se o ato fotográfico procurando compreender as relações que se estabelecem no processo fotográfico, o sujeito autor e o receptor. Fundamentado na teoria de Aumont (2004) procurou-se abordar a questão da percepção cognitiva das imagens e como se dá a representação da forma e do conteúdo a partir dessa concepção. Em seguida, procurou-se fazer uma abordagem sobre os pressupostos teóricos da análise documental da fotografia no campo da Ciência da Informação, pautada na análise de conteúdo de fotografias com base nos estudos de Pinto Molina, García Marco e Augustín Lacruz (2002), Del Valle Gastaminza (1999) e Robledano Arillo (2000); e na discussão dos princípios básicos da Arquivística, nesse ponto fez-se uma reflexão teórica e prática sobre o tratamento de fotografias em fundos documentários, tendo como parâmetro os documentos fotográficos do fundo da Faculdade de Filosofia e Ciências - FFC já investigados pelas pesquisadoras.

A metodologia consistiu na revisão da literatura que discute a ontologia do processo fotográfico, no campo das ciências sociais; na análise da literatura que contempla os aspectos teóricos e metodológicos da análise de conteúdo já consolidada, no campo da Ciência da Informação, e particularmente no campo da Biblioteconomia; bem como na investigação de obras e artigos que fundamentam o tratamento dos documentos na área da Arquivística (Bellotto, 2004; Schellenberg, 1980; Heredia Herrera, 1991; La TorresMerino e Martin-Palomino y Benito, 2000). Nesse momento foi possível fazer um confronto entre a teoria e a prática direcionada ao trata- mento de fotografias em fundos de arquivos, tendo como objeto os documentos fotográficos produzidos e acumulados pelo fundo FFC.

Dentre os resultados, verificou-se que, na análise do processo ontológico da fotografia, está a gênese da noção de forma e de conteúdo, importantes para os fundamentos do processo de análise documental das fotografias no campo da Ciência da Informação e da Arquivística; e a investigação dos fundamentos teóricos e epistemológicos da Arquivística forneceu elementos para a elaboração de uma proposta teórica e metodológica singular para o tratamento de fotografias na perspectiva da Arquivística. Constatou-se que a análise da forma e do conteúdo associada à teoria Arquivística apresentou elementos significativos que deverão ser considerados na construção de uma proposta teóricometodológica para o tratamento de fotografias em fundos de arquivos.

Diante do crescimento acentuado do volume de fotografias nos acervos pessoais e institucionais e das necessidades do acesso rápido e eficaz aos informacionais no mundo globalizado, tornase importante a produção de estudos comprometidos com aspectos teórico-práticos que vislumbrem a construção de um modelo teóricometodológico para análise documental de fotografias na perspectiva da Arquivística.

\section{A gênese da noção de forma e de conteúdo da fotografia}

No campo das Ciências Humanas, desde o século XIX, investigadores vêm procurando estudar a problemática da fotografia, nas mais diversas áreas do conhecimento (1) e em diferentes correntes de pensamento. Com base nos estudos de Dubois (1994) sobre o ato fotográfico, pretende-se demonstrar que no processo ontológico da fotografia está a origem da noção da forma e de conteúdo das imagens fotográficas. Nesse ponto também foi incluída a abordagem de Jacques Aumont (2004) sobre a percepção das imagens, na qual se enfatizou a questão da representação com base na percepção cognitiva.

\subsection{A ontologia do processo fotográfico: o ato fotográfico}

Dubois em sua obra o ato fotográfico e outros ensaios (1994) discute a ontologia da fotografia; a questão do analogon da fotografia com o real e a fotografia como código indiciário ou como mensagem. Ele faz uma análise profunda do percurso histórico das principais posições epistemológicas do século $X I X$ até o século $X X$, fornecendo um panorama histórico no qual se 
contextualiza a questão da verossimilhança da fotografia com o real até sua superação. Seu estudo fundamenta-se na semiótica de Peirce (1978, apud Dubois, 1994), de Barthes (1984) e, sobretudo na teoria de Bazin (1945) acerca da ontologia da fotografia. Ao investigar a fundo o ato fotográfico, Dubois (1994) procura demonstrar como se dá o processo de codificação da imagem antes e depois do "clic".

Com base nos conhecimentos da semiótica desenvolvidos por Pierce, Dubois (1994) considera que a fotografia no campo dos signos indiciários é uma impressão ao mesmo tempo separada, plana, luminosa e descontínua . Com base na semiótica, Dubois (1994) parte do princípio que imagem não é a priori mimética, ou seja, semelhante ao objeto, do qual é apenas um traço do real, marcas do registro. Por outro lado, fundamentado na teoria de Bazin (1945), defende que para se compreender o que constitui a originalidade da imagem fotográfica devemos obrigatoriamente ver o processo bem mais do que o produto, no nível mais elementar, das modalidades técnicas de constituição, bem como a relação destas com sua situação referencial no momento da produção.

Por isso, para Dubois (1994), não se pode pensar a imagem fotográfica fora do ato que a faz ser. No seu entender, a fotografia não é apenas uma imagem produto de uma técnica do "saberfazer", mas um trabalho que não se pode ser concebido fora de suas circunstâncias, porque a fotografia é ao mesmo tempo "imagem-ato".

Tanto Dubois (1994) como Sontag (2004) defendem em seus estudos o aprofundamento do ato fotográfico, já que este se formaliza na experiência entre o fotógrafo e o objeto a ser fotografado. Nesse sentido, na concepção de Dubois, o ato fotográfico é um processo no qual se deve examinar: o gesto do corte, o jogo do ato, bem como a questão espaço temporal da foto. Por isso, convém considerar a relação do sujeito autor e do sujeito espectador (ou receptor) com a fotografia.

A questão do espaço representado, e do espaço de representação, está relacionada à forma e ao conteúdo da fotografia em Dubois (1994, p. 209 -210), e deve-se observar que é sempre com relação ao espaço de representação que é organizada, "dentro do campo", a figura do espaço representado.

Conforme Dubois (1994), o espaço de representação é antes pensado e planejado pelo fotógrafo no ato da tomada e do corte, que faz o enquadramento com base nos padrões de organização e de composição, determinados culturalmente, no qual circunscrevem forma de enqua- dramento, posições (direita, esquerda, alto, baixo, centro) e proporções.

No "corte" o espaço é selecionado, a representação originalmente circular é padronizada pela forma retangular, e nesse processo ocorre a "quadrificação" do espaço de inscrição de modo arbitrário. Na tomada, o corte do espaço temporal é gerado simultaneamente no mesmo movimento. Desse modo, a noção de corte contextualiza-se no tempo e no espaço.

Ao abordar o antes e o depois da tomada Dubois descreve que: primeiro o fotógrafo planeja cuidadosamente a tomada da imagem levando em conta o padrão de representação de forma e composição. Após o clic da tomada, o que foi fixado, é inscrito e "recortado" como "fatia" do espaço-tempo. A foto no seu sentido pragmático passa a fazer parte de um novo mundo, de um passado, do "isso foi"; ao mesmo tempo é inscrita no mundo dos códigos, possuindo um significado ou vários significados. É aqui que se insere, particularmente, a questão conteúdo fotografia, e como vai ser representada pela leitura da imagem-ato.

Logo após o ato, a fotografia entra no mundo dos códigos, ou seja, nela se imprimem novos significados. Desse modo, a leitura da imagem pode ser feita tanto pelo autor quanto pelo espectador. Nesse jogo considera-se um conjunto de elementos, tais como: a visão de mundo do espectador, o conhecimento de códigos, a ideologia, a religião e a cultura do sujeito que lê a foto, e que Ihe atribui significado. Por mais que se queira, a representação de um documento fotográfico não é neutra, este é um dos pontos que vem sendo tratado desde o final do século XIX pelos estudos críticos da mimese. Dentre estes se destacam aqui o trabalho de Dubois (1994) no campo da semiótica e os estudos de Aumont (2004) fundamentados na percepção cognitiva no campo da psicologia, que será exposta a seguir.

\subsection{A percepção da forma e do conteúdo}

Nosso modo de relação com o mundo é pictórico, em outras palavras, uma das formas de nos relacionarmos com o mundo é construída por meio das representações que fazemos a partir de imagens. Mas o que é a representação da fotografia? De acordo com Aumont (2004), a representação é um processo pelo qual se institui um representante que, em certo contexto limitado, toma lugar explicitamente destinado a essa função.

Conforme Aumont (2004), ao se olhar uma fotografia percebe-se simultaneamente uma dupla 
realidade: a imagem como fragmento de superfície plana e como fragmento de espaço tridimensional. No seu entender, a imagem é percebida, quase de modo automático, por uma interpretação em termos espaciais e tridimensionais. Isso diz respeito à percepção da forma como unidade, como configuração que implica a existência de um todo que estrutura suas partes de maneira racional. Além disso, a percepção da forma é inseparável não só da percepção das bordas, mas relativa aos objetos figurados. Nesse sentido ao se olhar a foto que tem o gato referente, vemos não só o gato, mas as bordas, ou seja, o enquadramento, conforme Dubois (1994), o corte feito durante a tomada.

Em Aumont (2004) encontra-se o conceito de forma como estrutura perceptível pelo sujeito espectador que visualiza a cena. A estrutura é ao mesmo tempo plana e tridimensional. Porém, a forma é uma convenção determinada sócioculturalmente.

Entende-se que essa noção de "imagem-ato" desenvolvida por Dubois, na qual a forma e o conteúdo compreendem também a abordagem da relação do sujeito autor e do sujeito espectador com a fotografia, trata de aspectos relevantes para a abordagem teórica da fotografia documental na área das ciências da Informação, e particularmente, para a arquivística.

\subsubsection{A forma e o conteúdo: o sentido da ima-} gem

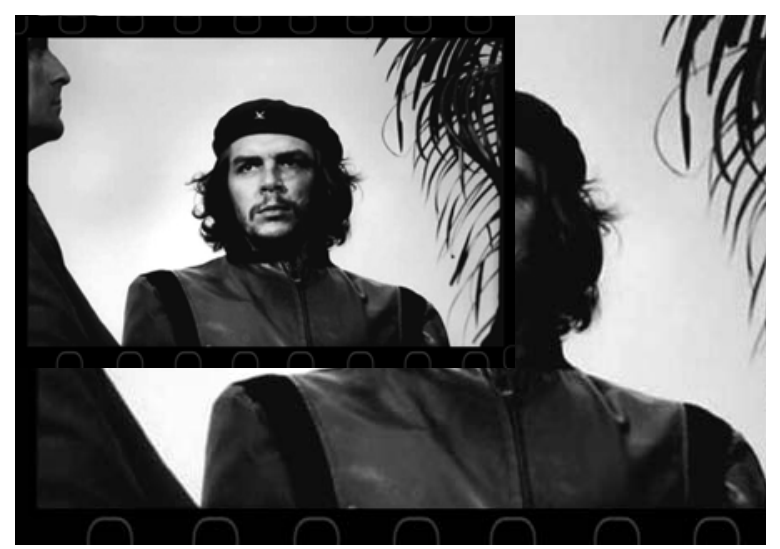

Figura 1. Ernesto Che Guevara (Fotógrafo: Alberto Korda - Cuba, 05 março, 1960. Fonte: www.patria grande.net/cuba/ernesto.che.guevara/index.htm)

Com base na concepção de Aumont (2004) e Dubois (1994) pretende-se fazer uma breve análise da forma e do conteúdo da fotografia de Che Guevara (Figura 1) produzida por Alberto Korda na década de sessenta. Se esta imagem fosse reproduzida em miniatura, mesmo assim seria possível reconhecer a forma de um ser humano, porque que as unidades (cabeça, pescoço e braço) que estruturam o todo mantêm as noções de proporções.

Quanto à questão do conteúdo, Aumont (2004) e Dubois (1994) concebem que uma imagem é ao mesmo tempo universal e particular. Conforme o autor, a particularidade dessa imagem está relacionada ao poder de singularidade da fotografia na semiótica peirciana, na qual a fotografia como índice mantém uma conexão física com o seu referente, como traço de evidência do real. Em outras palavras, a imagem de Che Guevara possui uma conexão física com seu referente, pois ele existiu na realidade, mas esta não passa de um traço do real.

Conforme Aumont (2004), a singularidade da imagem de Che Guevara (Figura 1) nos remete à noção de espaço-tempo, e ao sentido que the é dado no processo de representação no momento em que a mesma é submetida à leitura, levando-se em conta a percepção do sujeito histórico. Dessa forma, ao olhar a foto de Che Guevara o sujeito espectador poderá fazer ou não questões tais como: Quem foi Che Guevara? Um revolucionário? Um rebelde comunista, ou, nos termos de hoje, um terrorista?

O referente Che Guevara (Figura 1) existiu, e sua imagem vem sendo cultuada como símbolo de resistência ao imperialismo norte-americano, e por isso está situada historicamente no tempo e no espaço. Essa foi uma das fotografias que conseguiu, literalmente, "embalsamar o tempo", tornando-se um "documento monumento", pelo valor social atribuído ao seu referente, desfrutando hoje de um status de documento que já faz parte da memória coletiva da sociedade latino-americana.

Portanto, para Aumont (2004), o espectador é quem dá o sentido da imagem, a partir de sua percepção, que não é neutra. No caso da representação da fotografia acima citada, ela possui vários sentidos e múltiplos significados, e estes dependem da concepção de mundo do sujeito que a interpreta, de sua ideologia e da cultura na qual se encontra inserido o sujeito receptor. Assim, o conteúdo de uma imagem varia conforme o contexto de sua produção, dos desejos de usos e valores que thes são atribuídos, sobretudo se levarmos em conta a condição do sujeito que se propõe a interpretar uma imagem.

\section{Os pressupostos teóricos da análise documental da fotografia no campo da Ciência da Informação}

Como o nosso propósito é o aprofundamento teórico sobre a questão da análise documental 
da fotografia, enfatizaremos aqui a abordagem teórica de Pinto Molina; Garcia Marco e Augustin Lacruz (2002), por considerá-la relevante para a representação da forma e do conteúdo da fotografia no campo da Ciência da Informação. Esses estudiosos defendem que (Pinto Molina, García Marco, Augustín Lacruz, 2002, p. 82).:

Dependendo da perspectiva adotada poderá se encontrar nos documentos icônicos três subestruturas que se superpõem, atuam e se reforçam mutuamente: representativa, abstrata e simbólica

Conforme essa concepção, a estrutura representativa ou superficial da imagem refere-se à realidade física, trata-se da representação da informação de forma direta, o que se vê na foto. A estrutura abstrata ou profunda dos documentos imagéticos refere-se à representação com base nos aspectos cognitivos e sensitivos.

A estrutura simbólica dos documentos visuais (Pinto Molina, García Marco, Augustín Lacruz, 2002, p 82-83).

nos remete ao sistema complexo de significados atribuídos que se empregam na mensagem visual e que são reconhecidos universalmente por uma determinada comunidade de usuários, tal como a linguagem e os números.

Esses estudiosos entendem que os documentos fotográficos podem se caracterizar em função da importância relativa dessas três subestruturas: representativa, abstrata e simbólica. Nesse sentido, o documento fotográfico será representativo quando sua estrutura representativa predominar sobre as estruturas abstrata e simbóli$\mathrm{ca}$, de modo que o protagonista de cada estrutura determine o tipo de representação.

\subsection{A análise de conteúdo da fotografia}

Para Del Valle Gastaminza (1999) e Robledano Arillo (2000), a análise documentária da fotografia tem como objetivo primordial a recuperação dos documentos a partir de distintos critérios: formais, morfológicos ou temáticos, geralmente normalizados.

Conforme Robledano Arillo (2000) a análise de conteúdo tem como objetivo gerar uma representação que permita a recuperação do conteúdo das imagens do fundo.

Geralmente, a análise documental da imagem realiza-se em três níveis de conteúdo: o morfológico, o temático e o icônico. A análise morfológica preocupa-se com a forma do conteúdo, ou seja, com os atributos técnicos utilizados para obtenção da imagem. Na análise do conteúdo temático, os elementos de conteúdo presentes na foto são abstraídos pelo pensamento intelectual e se convertem em conceitos ou categorias temáticas. A análise do conteúdo icônico consiste na descrição do que se vê literalmente na fotografia (Robledano Arillo, 2000, p. 270).

Entende-se que essas categorias utilizadas para a realização do processo de análise de conteúdo podem ser compreendidas quando contextualizadas nos pressupostos teóricos do trabalho de Pinto Molina; García Marco e Augustín Lacruz (2002), que entendem que a análise de conteúdo da imagem deverá levar em conta todas e cada uma de suas estruturas: representativa, abstrata e simbólica.

Nesse sentido, o processo de análise documental da fotografia requer um conhecimento acerca da imagem fotográfica, de modo que o documentalista compreenda o que está representado.

Apesar dos teóricos reconhecerem a importância da representação da estrutura abstrata e simbólica da fotografia, ao examinar a literatura que discute a análise de conteúdo da fotografia tanto na Biblioteconomia como na Arquivística, é fácil constatar que, na prática, persegue-se a representação da estrutura representativa ou superficial da fotografia.

Esse argumento pode ser reforçado da seguinte forma: primeiro, com base na teoria de Pinto Molina, García Marco e Augustín Lacruz (2002, 90), que aponta que a análise representativa preocupa-se em descrever as técnicas de produção das imagens, sua localização no espaçotemporal, os seres vivos e suas ações.

Além disso, procura descrever o contexto geral, relacionado ao primeiro plano da composição, recorrendo-se tão somente ao segundo quando este altere significativamente a informação registrada pelo primeiro.

Segundo, verifica-se que a estrutura representativa predomina na descrição denotativa dos elementos visuais que aparecem na foto.

Terceiro, para se descrever as estruturas representativa, abstrata e simbólica da fotografia documental exige-se a objetividade por parte do analista, que não deve emitir qualquer juízo de valor. Paradoxalmente, cabe ao mesmo saber que uma imagem icônica dificilmente significa, de forma unívoca, um termo abstrato, por isso, defende-se o uso de termos concretos, deixando-se para o usuário a liberdade de atribuir os termos abstratos que lhe pareçam mais convenientes (Pinto Molina, García Marco e Augustín Lacruz, 2002). 
Continuando esse raciocínio, os autores concebem que a representação icônica próxima da realidade tão necessária à fotografia documental requer do profissional um distanciamento máximo do objeto, no caso a fotografia. No entanto, como é sabido, descrever objetivamente uma imagem é quase impossível. Por outro lado, a leitura subjetiva procura fazer um aprofundamento do significado das mensagens icônicas procurando otimizar a interpretação.

Em resumo, na concepção de Pinto Molina, García Marco e Augustín Lacruz (2002), a noção de forma e de conteúdo da fotografia encontra-se presente nas estruturas representativa, abstrata e simbólica. No entanto, a noção de forma aparece mais clara na descrição da estrutura representativa.

\subsection{Os princípios fundamentais da teoria e da prática Arquivística}

Na concepção da Arquivística clássica e moderna, os documentos arquivísticos são de natureza orgânica, produzidos por uma entidade pública ou privada, família ou pessoa, em decorrência das atividades e funções desempenhadas durante a sua existência.

Devido a sua origem, Rousseau e Couture (1998) defendem que os documentos de arquivos geram as "informações orgânicas". Nesse sentido, o valor dos documentos está no seu conjunto. Quando reunidos num fundo, o arquivo de uma pessoa física ou jurídica possui valor de prova e testemunho administrativo, legal e histórico, e vem justapor-se ao valor de informação que cada documento possui dentro do fundo.

Ao longo de sua história, a Arquivística apresentou conotações ligadas às questões de natureza prática em relação aos documentos e a sua constituição como ciência. A construção do conhecimento nesse campo foi marcada por dois fatos que ocorreram durante o século XIX: a elaboração do princípio do respect des fonds (1841), por Natalis de Wally, a partir do qual se passou a defender o agrupamento dos documentos por fundos; e a publicação do princípio da proveniência no Manual for the arrangement and description of archives dos arquivistas holandeses (Muller, Feith e Fruin, 1898). Conforme o princípio do respect des fonds, os arquivos ou fundos de arquivos não devem jamais se misturar com outros de procedência diferente. O princípio da proveniência estabelece que os documentos de cada arquivo ou fundo de arquivo devem manter a classificação e a ordem que a própria instituição the deu na sua origem, isto é, deve refletir a organização interna de cada insti- tuição. Esses dois princípios são universalmente aceitos como base da arquivística teórica e prática (Bellotto, 2004, p. 129-130).

Para efeito desse estudo, o conceito de arquivo deve ser entendido como conjunto de documentos produzidos e acumulados organicamente. Nesse sentido será utilizado como similar de fundo documental.

O fundo compreende documentos gerados/recebidos por entidades físicas ou jurídicas, necessários à sua criação, ao seu funcionamento e ao exercício de atividades que justifiquem a sua existência mesma, descartando-se, assim, a caracterização de coleção de documentos reunidos por diversas razões, que não administrativas

Assim, o conceito de fundo compreende o conjunto total de documentos produzidos, recebidos e acumulados por uma pessoa física ou jurídica, pública ou privada, que se originaram como produto de suas atividades e funções desenvolvidas durante a sua existência. Desse modo, o conjunto de documentos fotográficos produzidos e acumulados pela Faculdade de Filosofia e Ciências FFC - Campus de Marília faz parte do arquivo, ou Fundo da Faculdade de Filosofia e Ciências, já que os referidos documentos possuem os atributos que os legitimam como documentos de arquivo.

A investigação dos fundos é uma etapa importante para qualquer tratamento documental na perspectiva da arquivística podendo realizar-se desde o arquivo corrente até os arquivos permanentes.

Com base na Arquivística contemporânea, de origem espanhola, particularmente da Escuela Iberoamericana de Archivos de Madri, na qual se situa o estudo de La Torre Merino e MartinPalomino y Benito (2000), considera-se que o tratamento documental na perspectiva da Arquivística deverá ser iniciado pela identificação do fundo. A identificação do fundo corresponde em linhas gerais à investigação profunda do sujeito produtor, de suas funções e atividades que deram origem à documentação produzida e acumulada. Em resumo, a identificação fornece elementos para as demais etapas do processo de tratamento do fundo, tal como a organização do fundo, com o estabelecimento do quadro de classificação e ordenação de suas séries documentais, além de fornecer as bases para sua posterior avaliação e descrição.

\subsubsection{A representação da forma e do conteúdo da fotografia na Arquivística}

A estudiosa dos arquivos Heredia Herrera (1991) considera que Schellenberg foi precursor dos estudos sobre o método de descrição em- 
pregado pela Arquivística. Ao analisar sua obra, verifica-se que no final da década de 50 o referido estudioso já afirmava que os documentos de arquivos podem ser caracterizados tanto pela sua estrutura física como pela substância (Schellenberg, 1980, p. 235-237). Essa estrutura física está relacionada aos elementos ou caracteres externos dos documentos, a partir dos quais se descrevem o gênero, o suporte, o formato, o volume e a quantidade.

Já as características relativas a sua substância se encontram tanto na proveniência quanto nas origens funcionais, na data, lugar da produção, assunto ou matéria. Esse caráter funcional é o mais importante, pois está ligado às atividades e funções que deram origem ao documento (Schellenberg, 1980, p. 232). Conforme Bellotto (2002, p. 26) a substância é a essência, a razão de existir do documento, o conteúdo que o tornará único no seu contexto de produção e utilização. Tanto para Schellenberg (1980) como para Bellotto (2002), a substância dos documentos está diretamente relacionada à proveniência, ou seja, aos caracteres internos dos próprios documentos.

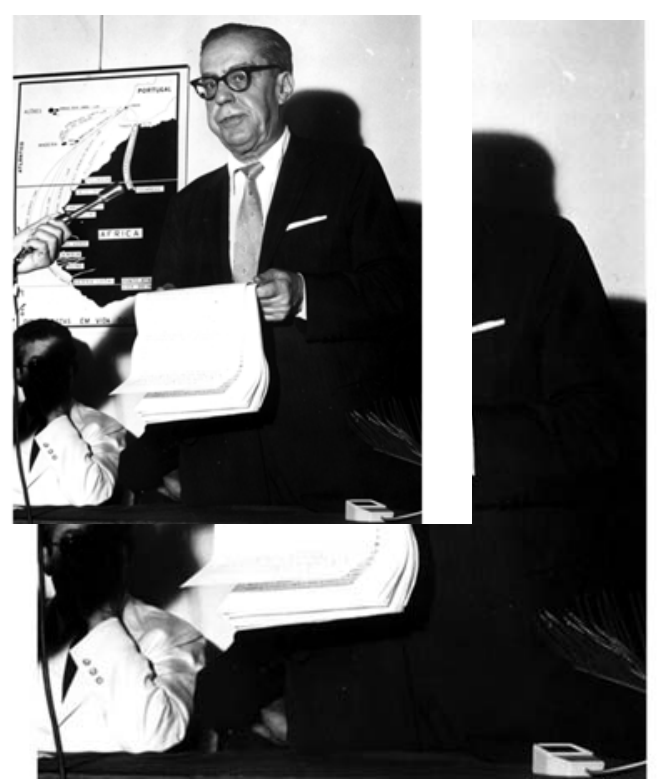

Apresentação de conferência do Prof. Dr. Sérgio Buarque de Holanda (USP), na "Semana de Estudos Henriquinos", promovida pelo Departamento de História, da Faculdade de Filosofia, Ciência e Letras de Marília - FAFI. Anfiteatro da FAFI, MaríliaSP, 18.10.1960. 1. Prof. Dr. Sérgio Buarque de Holanda (USP); 2. Pessoa não identificada."

Figura 2. Fotografia $C C D H 40$

(Fonte: Memorial Fotográfico da FFC)

Conforme a lógica do raciocínio do método de descrição apresentada por Schellenberg (1980) quanto às características relativas à substância ou essência dos documentos, o arquivista deveria utilizar-se do seguinte: QUEM para entidade/pessoa com a finalidade de descobrir a proveniência do documento; COMO para investigar qual a função orgânica motivou a produção do documento; QUANDO para saber a data da produção da unidade documental; e ONDE para determinar o lugar da produção da unidade documental.

Entende-se que essa análise de Schellenberg (1980) criou uma identidade para o método arquivístico ao contemplar a investigação dos atributos substanciais dos documentos, com base na proveniência documental relacionada à função/atividade geradora dos documentos, remetendo-nos à construção do contexto de produção dos documentos. Questionamos de que modo o estudo proposto por Schellenberg (1980) poderia nos auxiliar: 1) quanto à noção de forma e de conteúdo dos documentos fotográficos na perspectiva da Arquivística; e 2) como representar o documento ilustrado na imagem fotográfica (Figura 2).

A nossa preocupação em elucidar os obstáculos sobre as dificuldades de tratamento dos documentos fotográficos, em fundos arquivísticos, principalmente em relação à etapa da descrição, levou-nos à reflexão descrita no Quadro 1 que tem como objetivo demonstrar a investigação das características relativas à substância dos documentos na análise documental arquivística, voltada para os documentos fotográficos.

\begin{tabular}{lll}
\hline Pergunta & Características & Descrição \\
\hline Quem & Proveniência & Sujeito produtor \\
& & Departamento de História, da \\
& Faculdade de Filosofia, \\
& & Ciências e Letras de Marília - \\
& & FAFI. \\
\hline Como & Função & Função orgânica motivou a \\
& & produção documental \\
& & [Ensno/atividade \\
& & extracurricular] \\
& [Apresentação de conferência \\
& do prof. Dr. Sergio Buarque \\
& de Holanda, na "Semana de \\
& & Estudos Henriquinos"] \\
\hline Quando & Data que foi produzida a \\
& & unidade documental. \\
& & [18/10/1960] \\
& & Em que lugar se produziu a \\
& & referida unidade documental. \\
& & [Anfiteatro da FAFI, Marília- \\
& SP] \\
\hline Onde & Local &
\end{tabular}

Quadro 1. Características relativas à substância dos documentos, evidenciadas com base na Arquivística.

Fonte: elaborado conforme teoria de Schellenberg 
(1980, p. 235- 237) e Fotografia CCDH 40 - Memorial Fotográfico da FFC.

Portanto, o Quadro 1 poderá nos auxiliar na investigação das características substanciais dos documentos, com base nas respostas vinculadas aos elementos da Arquivística, ao mesmo tempo em que fornece as bases para a identificação, classificação e descrição das informações nas etapas posteriores. A substância do documento, representado pela Figura 2, está relacionada à proveniência do documento, ou seja, quem motivou a criação da fotografia, a data e o lugar. É a proveniência quem determina o contexto de produção das imagens.

As características essenciais dos documentos referem-se tanto à estrutura quanto à substância. Para Schellenberg (1980) o método descritivo iniciava-se com a descrição da estrutura do documento, ou seja, com a investigação de caracteres externos, tais como: gênero, forma, composição, volume, quantidade etc.

Entende-se que essa etapa de investigação corresponderia à análise de conteúdo morfológico da fotografia abordada por vários autores (Moreiro Gonzalez, 1994; Del Valle Gastaminza, 1999; Robledano Arillo, 2000), no campo da Ciência da Informação.

Portanto, esse método de descrição que parte das características relativas à estrutura e substância dos documentos pode ser concebido como um dos subsídios para a análise dos documentos fotográficos porque fornece os elementos básicos relativos à proveniência, além disso, nos remete a noção de forma e conteúdo na perspectiva da Arquivística.

\section{Considerações finais}

$\mathrm{Na}$ análise do processo ontológico da fotografia está a gênese da noção de forma e de conteúdo, importantes para os fundamentos do processo de análise documental das fotografias no campo da Ciência da Informação e da Arquivística.

Os estudos realizados, campo das ciências sociais, como os de Dubois e Aumont poderão contribuir de forma significativa para a compreensão da problemática da fotografia no campo da Ciência Informação, particularmente na área da Arquivística que ainda apresenta lacunas no campo do saber e do fazer em relação ao tratamento dos documentos fotográficos.

Constatou-se que o processo de tratamento de fotografias em fundos arquivísticos requer uma análise profunda de seus caracteres externos internos, em outras palavras exige que o analista saiba distinguir as estruturas: representativa, abstrata e simbólica da imagem fotográfica levando sempre em conta o contexto de produção, a proveniência documental e as relações que o documento mantém com os demais documentos do fundo.

A investigação dos fundamentos teóricos e epistemológicos da Arquivística forneceu elementos para a elaboração de uma proposta teórica e metodológica para o tratamento de fotografias na perspectiva da Arquivística.

Diante do crescimento acentuado do volume de fotografias nos acervos pessoais e institucionais e das necessidades do rápido acesso aos conteúdos informacionais no mundo globalizado torna-se fundamental a elaboração novos estudos comprometidos com os aspectos teóricos e práticos no sentido de promover o adequado tratamento dos documentos fotográficos de um fundo de arquivo. Nesse sentido, recomenda-se a fomentação de estudos que vislumbrem o desenho de proposta teórica e metodológica que possibilite a análise documental de fotografias na perspectiva da Arquivística.

\section{Notas}

(1) Dentre os quais se destacam os estudos no campo da Semiologia: as obras Écrits sur le signe, de Charles Sanders Peirce (apud Dubois , 1994)), a Câmara Clara, de Roland Barthes (1984) e O ato fotográfico e outros ensaios de Philippe Dubois (1994); no campo da História; no campo da Sociologia, a obra Sobre fotografia e outros ensaios, de Susan Sontag (2004), no campo da Antropologia, Les Cahiers du Cinéma, publicados na França, na década de 70; e na Psicologia cognitiva, sobretudo A Imagem, de Jacques Aumont ( 2004).

\section{Referências}

Aumont, Jacques (2004). A imagem. 8. ed. Trad. Estela dos Santos Abreu e Cláudio César Santoro. Campinas-SP: Papirus, 2004.

Barthes, Roland (1984). A câmara clara. Nota sobre fotografia. Trad. Julio Castañon Guimarães. Rio de Janeiro: Nova Fronteira, 1984.

Bazin, André (1975). Ontologie de l'image photogrgraphie (1945), em quést-ce que le cinéma?. Paris, Ed.du Cerf, 1975. Tomo I.

Bellotto, Heloísa, Liberalli (2002). Como fazer análise diplomática de documentos de arquivo. São Paulo: Arquivo do Estado, Imprensa Oficial do Estado, 2002. (Projeto como fazer).

Bellotto, Heloísa, Liberalli (2004). Arquivos permanentes: tratamento documental. 2. ed.rev.e ampl. Rio de Janeiro: Editora FGV, 2004.

Del Valle Gastaminza, Félix (1999). Documentación Fotográfica. Madrid: Editorial Síntesis, 1999. 
Heredia Herrera, Antonia. (1991). Archivística general teoría y práctica. 5. ed. Sevilla: Diputación Provincial de SeviIla, 1991.

Dubois, Philippe. (1994). O ato fotográfico e outros ensaios. Trad. Marina Appenzeller. Campinas, SP: Papirus, 1994. (Coleção ofício de arte e forma).

La Torre Merino, José Luís; Martin-Palomino y Benito, Mercedes (2000). Metodología para la identificación y valoración de fondos documentales. Madrid: ministerio de Educación, Cultura y Deporte, S.G. de información y publicaciones, 2000. (Escuela Iberoamericana de archivos: experiencias y materiales).

Moreiro Gonzalez, José Antonio (1994). Análisis de imágenes: un enfoque complementario // Pinto Molina, $\mathrm{M}$ et al. Catalogación de documentos: teoría y práctica. Madrid: Síntesis, 1994.

Muller, Feith \& Fruin, R. (1940). Manual for the arrangement and description of archives. Trad. Arthur H. Leavitt. New York, 1940.

Pinto Molina, M.; Garcia Marco, F. J.; Augustin Lacruz, M. C. (2002). Indización y resumen de documentos digitales y multimedia: técnicas y procedimientos. España: ediciones Trea, S. L, 2002.

Robledano Arillo, Jesus (2000). Documentación fotográfica em medios de comunicación social. // Moreiro, José Antonio (Coord.). Manual de documentación informativa. Madrid: Cátedra, 2000

Rousseau, J.; Couture, C. (1998). Os fundamentos da disciplina arquivística. Trad. Bigotte de Figueiredo. Lisboa: Publicações Dom Quixote, 1998.

Schellenberg, Theodore R. (1980). Documentos públicos e privados: arranjo e descrição. 2. ed. Trad. Nilza Teixeira Soares. Rio de Janeiro: Editora FGV, 1980.

Silva, Irisneide de Oliveira Souza; Fujita, Mariângela Spotti Lopes (2007). Aspectos teórico-metodológicos que envolvem a análise de conteúdo e de contexto de produção da imagem fotográfica como metodologias de tratamento do fundo FFC. // VII Congreso de Archivología del Mercosur - Archivos: Patrimônio Documental del futuro, 21-24 de novembro 2007, Viña del Mar, Chile. Anais ... Vinã del Mar, Chile: ASOARCH, 2007, v. CD-ROM.

Smit, Johanna W. (1996). A representação da imagem. // Informare. Rio de Janeiro. 2:2 (jun./dez.1996) 28-36.

Sontag, Susan (2004). Ensaios sobre fotografia. São Paulo: Companhia das Letras: 2004. 